\title{
Adsorptive Removal of Cesium lons Using Prussian Blue Immobilized Coffee Ground Biochar
}

\author{
Youngsu $\operatorname{Lim}^{1 \odot} \cdot{\text { Dongwoo } \mathrm{Kim}^{2 \odot} \cdot \text { Jiseon Jang }}^{3 \oplus} \cdot$ Bolam Kim$^{1 \odot} \cdot$ Dae Sung Lee ${ }^{1,+\odot}$ \\ ${ }^{1}$ Departments of Environmental Engineering, Kyungpook National University \\ ${ }^{2}$ Environment Management Corporation \\ ${ }^{3}$ R\&D Institute of Radioactive Wastes, Korea Radioactive Waste Agency
}

(Received April 2, 2021; Revised May 6, 2021; Accepted May 6, 2021)

Objectives: Among various radioactive contaminants, radioactive cesium is one of the most harmful radionuclides that causes human health issues due to its high emission of gamma-ray, high solubility, high mobility, high fission yield, and long half-life. Different kinds of adsorbents have been developed for the removal of cesium from radioactive wastewater. Especially, biochar has attracted great attention as a potential adsorbent in the treatment of pollutants and for water purification. In addition, Prussian blue is a cubic lattice structure that contains a cage size similar to the hydrated cesium ionic radius, indicating it can selectively remove cesium ions. Therefore, the aim of this study is to investigate the cesium adsorption performance of synthesized Prussian blue-immobilized coffee ground biochar (PB-CGBC) under various experimental conditions for cesium removal from radioactive wastewater.

Methods: After wasted coffee ground was washed and dried, it was heated at $400^{\circ} \mathrm{C}$ with $10^{\circ} \mathrm{C} / \mathrm{min}$ of heating rate and $5 \mathrm{~h}$ of retention time in a furnace with little or no available air. The PB-CGBC was synthesized using a facile co-precipitation method. Fourier transform-infrared spectroscopy, X-ray diffractometer, field emission-transmission electron microscope, Brunauer-Emmett-Teller, and zeta potential analyzer were used to analyze physico-chemical characteristics and surface structure of the synthesized adsorbents. The kinetic and equilibrium experiments of cesium adsorption on PB-CGBC were carried out and the effect of $\mathrm{pH}$, temperature, initial cesium concentration, and contact time were also investigated in a batch system.

Results and Discussion: The characteristic analysis clearly confirmed the successful synthesis of PB-CGBC, indicating its abundant functional groups and special surface structure. In the batch study, it was found that the cesium adsorption onto the PB-CGBC was exothermic nature. The Elovich kinetic model and Temkin isotherm also provided a good correlation with the cesium adsorption reaction onto the PB-CGBC. The maximum adsorption capacity of PB-CGBC for cesium was $129.57 \mathrm{mg} / \mathrm{g}$ at $15^{\circ} \mathrm{C}$ and $\mathrm{pH} 8$ at $40 \mathrm{mM}$ of an initial cesium concentration, which was one of the highest values among those of previously reported adsorbents.

Conclusions: In this study, the PB-CGBC was synthesized by immobilizing Prussian blue to the surface of coffee ground biochar and successfully applied for the adsorptive removal of cesium ions. Based on the experimental results, the synthesized PB-CGBC can be served as a great adsorbent for treatment of wastewater polluted with radioactive cesium.

Keywords: Radioactive Cesium, Biochar, Prussian Blue, Adsorption

The Korean text of this paper can be translated into multiple languages on the website of http://jksee.or.kr through Google Translator. 


\title{
연구논문
}

\section{프러시안 블루를 담지한 커피박 바이오차의 세슘 흡착 제거}

\author{
임영수 ${ }^{1 \oplus} \cdot$ 김동우 $^{2 \oplus} \cdot$ 장지선 $^{3 \oplus} \cdot$ 김보람 $^{1 \oplus} \cdot$ 이대성 $^{1,+\infty}$ \\ ${ }^{1}$ 경북대학교 공과대학 환경공학과 \\ 2환경시설관리주식회사 \\ 3한국원자력환경공단 방사성폐기물연구소
}

목적: 방사성 세슘은 높은 감마선 방출량, 높은 용해성, 높은 이동성, 높은 핵분열율과 긴 반감기 때문에 인체에 가 장 큰 악영향을 주는 방사성핵종 가운데 하나로 분류된다. 현재까지 다양한 흡착제가 액체 방사성폐기물 내 세슘 을 제거하기 위해 개발되었다. 특히, 바이오차는 오염물질 처리와 수질 정화에 탁월한 흡착제로서 많은 주목을 받 고 있다. 또한, 프러시안 블루는 면심입방구조체로서 수화된 세슘이온과 비슷한 크기의 격자구조를 가지고 있어 선 택적인 세슘 제거가 가능하다. 따라서, 본 연구에서는 액체 방사성 폐기물 내 세슘 제거를 위해 다양한 실험 조건 에서 프러시안 블루로 담지된 커피박 바이오차(PB-CGBC)의 세슘 흡착 성능을 조사하고자 한다.

방법: 폐기된 커피박을 세척하고 건조시킨 후 $10^{\circ} \mathrm{C} / \mathrm{min}$ 의 열분해 속도와 5 시간의 체류시간, 공기가 없는 $400^{\circ} \mathrm{C}$ 조 건에서 열분해하였다. $\mathrm{PB}-\mathrm{CGBC}$ 는 간단한 공침법을 이용하여 합성하였다. 적외선/근적외선 분광광도계, $\mathrm{X}$ 선 회절 분석기, 전계방사형 투과전자현미경, 비표면적 및 기공도 측정기, 제타전위 분석기를 사용하여 흡착제의 물리·화학 적 특성과 표면 구조를 분석하였다. 회분식 실험을 바탕으로 $\mathrm{PB}-\mathrm{CGBC}$ 의 세슘 흡착에 대한 흡착속도와 평형실험 을 수행하였고 $\mathrm{pH}$, 온도, 초기 세슘 농도 및 반응시간에 대한 영향인자 실험도 함께 진행하였다.

결과 및 토의: $\mathrm{PB}-\mathrm{CGBC}$ 의 특성 분석 결과로부터, $\mathrm{PB}-\mathrm{CGBC}$ 표면에 풍부한 기능기 그룹이 존재하고 독특한 표면 구조를 가지고 있음을 확인할 수 있었다. 회분식 흡착 실험에서 $\mathrm{PB}-\mathrm{CGBC}$ 의 세슘 흡착이 발열반응이며 Elovich 속 도식과 Temkin 등온식이 PB-CGBC에 대한 세슘 흡착반응을 잘 나타냄을 확인할 수 있었다. $\mathrm{PB}-\mathrm{CGBC}$ 의 최대흡착 량은 $15^{\circ} \mathrm{C}$, 초기 세슘 농도 $40 \mathrm{mM}, \mathrm{pH} 8$ 에서 $129.57 \mathrm{mg} / \mathrm{g}$ 으로 나타났는데 이는 선행 연구된 흡착제들과 비교했 을 때, 가장 큰 값이었다.

결론: 커피박 바이오차 표면에 프러시안 블루을 담지하여 PB-CGBC를 합성하였으며, 이를 세슘 흡착제거에 성공 적으로 적용할 수 있었다. 실험결과로부터 $\mathrm{PB}-\mathrm{CGBC}$ 는 방사성 세슘으로 오염된 폐수를 처리하기 위한 훌륭한 흡 착제로서 사용할 수 있을 것이다.

주제어: 방사성 세슘, 바이오차, 프러시안 블루, 흡착

\section{1. 서론}

현재 국내에서는 24기의 원자력 발전소가 가동 중이며 2017 년 6월과 2019년 12월에 고리 1호기와 월성 1호기가 각각 영 구 정지되었다. 이에 따라 원자력 발전소 운전과정에서 발생 하는 원전폐기물과 함께, 영구 정지된 원자력 발전소의 제염 및 해체과정에서 다양한 방사성핵종을 포함한 많은 양의 액체 방사성폐기물이 발생할 것으로 예상된다. 방사성핵종 가운데 세슘은 원자로에서 우라늄의 핵분열 과정에서 약 $6 \%$ 의 높은 비율로 생성되며 액체 방사성 폐기물에서 저농도 $(0.003 \sim 0.31$ $\mu \mathrm{g} / \mathrm{L}$ )로 존재한다. ${ }^{1)}$ 특히, ${ }^{137} \mathrm{Cs}$ 은 약 30 년 정도의 긴 반감기
를 가지고 베타 붕괴를 거쳐 강한 감마선을 방출한다. 또한 높은 수용성과 휘발성으로 인해 생태계로 이동이 용이하기 때문에 생태계에 매우 높은 위험성을 주는 핵종으로 분류된 다. ${ }^{2)}$ 따라서 액체 방사성폐기물 내에 포함된 세슘을 효과적으 로 처리할 수 있는 소재 및 공정개발이 필요한 실정이다.

세슘의 처리 방법에는 이온교환법, 응집법, 침전법, 막여과법, 용매추출법, 역삼투법, 기포분리법, 흡착법 등이 있다. ${ }^{3,4)}$ 다른 처리법과 비교하여 흡착법은 처리 효율성이 높고, 공정이 간단 하며 적용이 쉽고, 에너지 소비가 없는 경제적인 방법이다. 대 표적인 세슘 흡착제는 제올라이트, 카올린, 몬모릴로나이트, 활 성탄, 인 몰리브덴산 암모늄(Ammonium molybdophosphate), 
바이오폴리머, 프러시안 블루(Prussian blue) 등이 있다. ${ }^{1,5)}$ 이 러한 다양한 흡착제 가운데 프러시안 블루는 진한 파란색의 색소로서, 다른 흡착제에 비해 제조가 쉽고 저렴하며 세슘 흡 착률이 높아 체르노빌 원자력발전 사고와 후쿠시마 방사능 유출 사고에서 방사성 세슘의 해독제로서 사용되었다. ${ }^{\circ}$ 프러 시안 블루가 높은 세슘 흡착률을 가지는 이유는 프러시안 블 루의 격자구조 크기가 수화된 세슘이온의 크기와 유사해 다른 일가 양이온 $\left(\mathrm{K}^{+}, \mathrm{Na}^{+}\right)$보다 세슘에 대해 높은 선택성을 갖기 때문이다. ${ }^{7-10)}$

바이오차는 바이오매스(농업부산물, 하수슬러지, 유기성 폐 기물 등)를 산소가 제한된 조건에서 열분해하여 제조한 탄소 성 물질이다. ${ }^{11,12)}$ 바이오차는 풍부한 표면 기능기, 넓은 비표 면적과 양이온 교환능력, 다양한 크기의 기공을 통해 수중의 양이온성 오염물질을 효과적으로 제거할 수 있는 것으로 알려 져 있다. ${ }^{13)}$ 최근 이러한 바이오차의 특성 때문에 농업 및 산림 부산물로 제조된 다양한 바이오차를 이용하여 물속의 세슘 제거에 관한 연구가 보고되었다. ${ }^{14-17)}$ 2019년 기준으로 국내 커피박 폐기물 발생 추정량은 약 15 만 톤으로, 커피 소비량 증가와 함께 꾸준히 증가하고 있는 추세이다. 이러한 커피박 폐기물은 다양한 유기탄소(셀룰로스, 헤미셀룰로스, 리그닌 등)와 산소 작용기(-OH, - $\mathrm{COOH}$ 등)를 포함하고 있어 바이오 차의 원료로서 굉장한 이점을 가지고 있다. ${ }^{18-20)}$ 현재까지 커 피박 바이오차 및 그 복합체를 이용하여 다양한 중금속(카드 륨, 니켈, 구리, 비소 등)과 염료(콩고레드, 메틸렌블루 등)의 흡착 반응과 흡착량에 대한 연구들이 보고되었지만, ${ }^{21-27)}$ 방사 성핵종인 세슘에 대한 흡착 연구는 아직 부족한 실정이다. 따 라서, 본 연구에서는 커피박 바이오차 표면을 프러시안 블루 로 담지한 흡착제를 합성하여 액체 방사성폐기물 내의 세슘 제거 성능을 평가하고자 한다.

\section{2. 실험방법}

\section{1. 실험재료 및 방법}

프러시안 블루 합성은 Iron(III) chloride hexahydrate $\left(\mathrm{FeCl}_{3} \cdot 6 \mathrm{H}_{2} \mathrm{O}\right.$, Daejung chemicals, Korea)와 Potassium hexacyanoferrate(II) trihydrate $\left(\mathrm{K}_{4}\left[\mathrm{Fe}(\mathrm{CN})_{6}\right] \cdot 3 \mathrm{H}_{2} \mathrm{O}\right.$, Daejung chemicals, Korea)를 사용하였다. 흡착 실험 시, 모의 폐수는 Cesium nitrate $\left(\mathrm{CsNO}_{3}\right.$, Sigma Aldrich, USA)를 초순수에 녹여 제조하였다. 바이오차 의 원료인 커피박은 대전의 한 커피 전문점에서 제공받았다. 증류수로 세척한 커피박 바이오매스를 세라믹 용기에 담은 후 질소가스로 산소 유입을 차단한 전기로 (Thermolyne 48000 , Thermolyne, USA)에 넣고 $10^{\circ} \mathrm{C} / \mathrm{min}$ 으로 승온하여 $400^{\circ} \mathrm{C}$ 에서 5 시간 동안 열분해하였다. 열분해 후, 상온까지 식힌 바이오차를 $1 \mathrm{~mm}$ 이하로 분쇄하여 아세톤과 증류수를 이용해 바이오차 표면 및 기공에 남아있는 불순물을 제거하고 $60^{\circ} \mathrm{C}$ 오븐에서 24 시간 이상 건조하였다.

\section{2. 프러시안 블루-바이오차 합성 및 특성 분석}

커피박 바이오차 $1 \mathrm{~g}$ 을 초순수 $200 \mathrm{~mL}$ 에 넣고 초음파 분쇄 기(Powersonic 620, Hwashin technology company, Korea)를 사용하여 약 1 시간 동안 분산시켰다. 분산된 용액에 $9 \mathrm{M}$ $\mathrm{FeCl}_{3} \cdot 6 \mathrm{H}_{2} \mathrm{O}$ 용액 $(170 \mathrm{~mL})$ 을 첨가하고 $90^{\circ} \mathrm{C}$ 에서 1 시간 동안 교반하였다. 이후, 교반된 용액에 $15.6 \mathrm{M} \mathrm{K}_{4}\left[\mathrm{Fe}(\mathrm{CN})_{6}\right] \cdot 3 \mathrm{H}_{2} \mathrm{O}$ 용액 $(85 \mathrm{~mL})$ 을 천천히 한 방울씩 주입하였다. 노란색에서 푸 른색으로 색 변화가 관찰되면 $90^{\circ} \mathrm{C}$ 에서 3 시간 동안 추가로 더 교반하였다. 다음으로 원심분리 과정을 거쳐 상등액을 제 거하고 침전된 반응물을 초순수로 5 회 이상 세척하였다. 마지 막으로 세척한 반응물을 $-70^{\circ} \mathrm{C}$ 에서 24 시간 동안 동결 건조하 고 건조된 흡착제를 막자사발로 곱게 분쇄하여 유리 바이알에 보관하였다. 합성에 사용한 프러시안 블루(Prussian blue), 커 피박 바이오차(Coffee ground biochar) 및 프러시안 블루를 담 지한 커피박 바이오차(Prussian blue immobilized coffee ground biochar)는 $\mathrm{PB}, \mathrm{CGBC}$ 및 $\mathrm{PB}-\mathrm{CGBC}$ 로 명명하였다. 흡 착제의 물리·화학적 특성 분석은 FT-IR (Fourier transforminfrared spectroscopy, PerkinElmer, USA), XRD (X-ray diffractometer, Rigaku, Japan), FE-TEM (Field emissiontransmission electron microscope, FEI company, Netherlands), BET (Brunaur-Emmett-Teller, BELSORP-max, Japan) 및 zeta potential analyzer (Otsuka, Japan)을 이용하였고 이를 통해 $\mathrm{CGBC}$ 와 $\mathrm{PB}-\mathrm{CGBC}$ 의 다양한 표면 기능기, 결정 및 입자 형태, 표면 구조/형태 유추 및 원소 구성을 확인하였다.

\section{3. 회분식 흡착 실험}

흡착성능평가는 회분식 실험을 통해 이루어졌다. 먼저, 50 $\mathrm{mL}$ 코니칼튜브에 $1 \mathrm{mM}$ 의 세슘 용액과 PB-CGBC $2.5 \mathrm{~g} / \mathrm{L}$ 넣고 $150 \mathrm{rpm}$ 에서 72시간 동안 교반하였다. 시료 용액의 $\mathrm{pH}$ 값은 $0.1 \mathrm{M} \mathrm{HCl}$ 과 $0.1 \mathrm{M} \mathrm{NaOH}$ 으로 조정하였다. 이후, 일정 시간 간격으로 반응한 용액을 샘플링 및 필터링 $(0.22 \mu \mathrm{m})$ 하였 고 샘플링 용액은 ICP-OES (Inductively coupled plasma-optical emission spectroscopy, PerkinElmer, USA)로 분석하였다. $\mathrm{PB}-\mathrm{CGBC}$ 의 흡착량 $\left(q_{\mathrm{e}}\right)$ 은 다음 식 (1)에 의해 계산하였다.

$$
q_{e}(m g / g)=\frac{\left(C_{o}-C_{e}\right)}{m} \times V
$$

여기서, $C_{o}(\mathrm{mg} / \mathrm{L})$ 는 수용액 상의 세슘이온의 초기 농도, $C_{e}(\mathrm{mg} / \mathrm{L})$ 는 수용액 상의 세슘이온의 평형 농도, $V(\mathrm{~L})$ 는 수용액 의 부피, $m(\mathrm{~g})$ 은 실험에 사용된 흡착제량을 의미한다. 흡착 영향 인자는 $\mathrm{pH}$ ( $4 \sim 10)$, 반응시간( $0.5 \sim 72$ 시간), 온도 $\left(15 \sim 35^{\circ} \mathrm{C}\right)$ 범위에서 조사하였고, 이 결과를 바탕으로 흡착속도 모델, 열 역학적 모델, 등온흡착모델에 적용하여 세슘 흡착 양상을 파 악하였다. 또한, 실험조건마다 최소 3 회 이상 반복실험을 진 행하였다. 

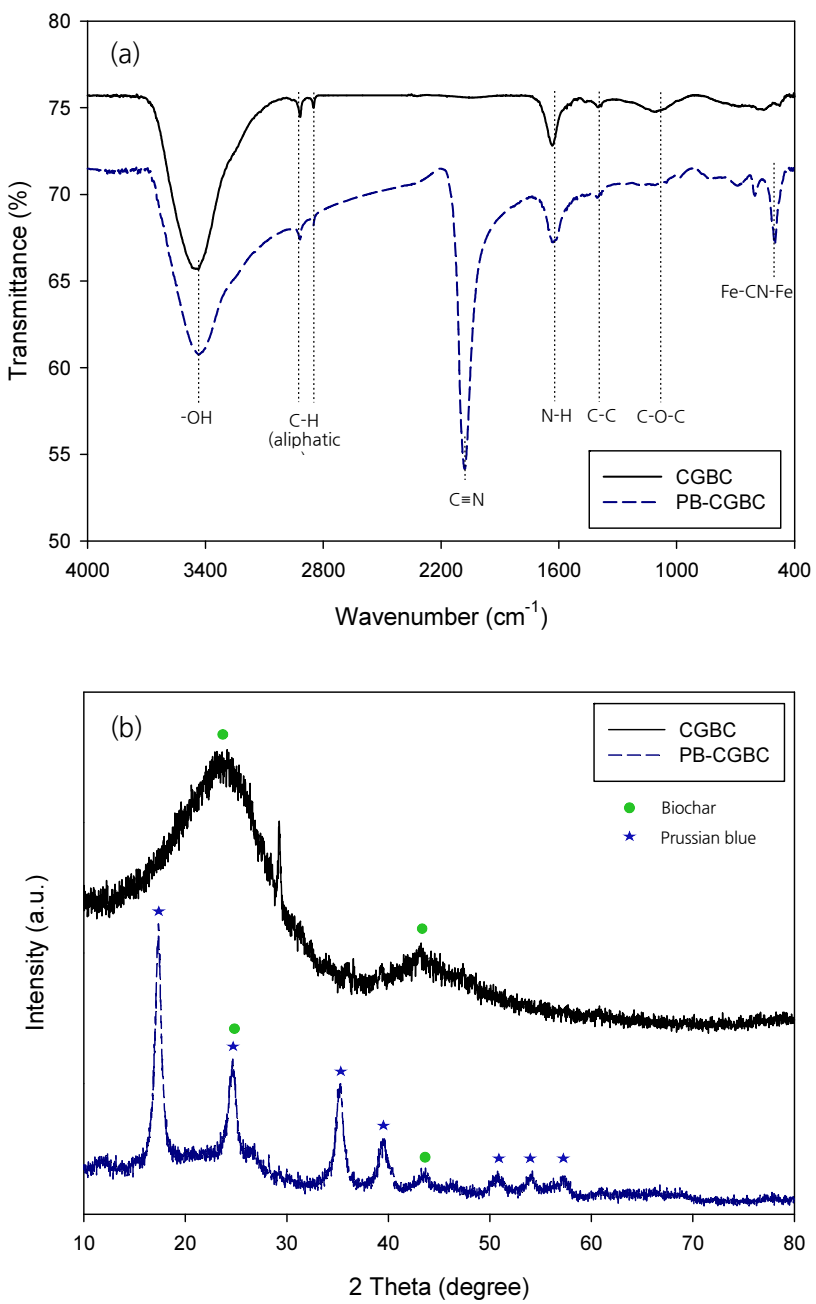

Fig. 1. Characterization of CGBC and PB-CGBC: (a) FT-IR spectra and (b) XRD patterns.

\section{3. 결과 및 고찰}

\section{1. 흡착제의 특성 분석}

$\mathrm{CGBC}$ 와 $\mathrm{PB}-\mathrm{CGBC}$ 의 표면기능기를 관찰하기 위해 FT-IR 분석을 실시하였다(Fig. 1(a)). CGBC와 $\mathrm{PB}-\mathrm{CGBC}$ 에서 공통 적으로 $3,500 \mathrm{~cm}^{-1}$ 에서 수산기 $(-\mathrm{OH}), 2,921 \mathrm{~cm}^{-1}$ 과 2,846 $\mathrm{cm}^{-1}$ 에서 지방족기 $(\mathrm{C}-\mathrm{H}), 1,600 \mathrm{~cm}^{-1}$ 에서 $\mathrm{N}-\mathrm{H}$ 기, 1,402 $\mathrm{cm}^{-1}$ 에서 방향족기 $(\mathrm{C}-\mathrm{C}), 1,109 \mathrm{~cm}^{-1}$ 에서 $\mathrm{C}-\mathrm{O}-\mathrm{C}$ 기가 발 견되었다. ${ }^{28-30)}$ 이들은 주로 바이오차에서 보편적으로 많이 관 찰되는 기능기들이다. 또한, 합성한 $\mathrm{PB}-\mathrm{CGBC}$ 의 $2,083 \mathrm{~cm}^{-1}$ 과 $499 \mathrm{~cm}^{-1}$ 에서 프러시안 블루의 $\mathrm{C} \equiv \mathrm{N}$ 기와 $\mathrm{Fe}-\mathrm{CN}-\mathrm{Fe}$ 기 가 관찰되었다. ${ }^{31)}$ Fig. 1(b)는 $\mathrm{CGBC}$ 와 $\mathrm{PB}-\mathrm{CGBC}$ 의 결정구조 를 관찰하기 위한 XRD 결과를 나타낸다. 먼저, $2 \theta=24^{\circ}$ 와 $2 \theta$ $=43^{\circ}$ 에서 바이오차에서 주로 발견되는 크고 넓은 회절피크가 관측되었으며, 이는 $\mathrm{CGBC}$ 와 $\mathrm{PB}-\mathrm{CGBC}$ 의 구조가 불규칙적 인 비결정성 구조라는 것을 나타낸다. ${ }^{32,33)} \mathrm{PB}-\mathrm{CGBC}$ 의 $2 \theta$ $=17^{\circ}, 24^{\circ}, 35^{\circ}, 39^{\circ}, 51^{\circ}, 54^{\circ}, 57^{\circ}$ 에서는 프러시안 블루에서
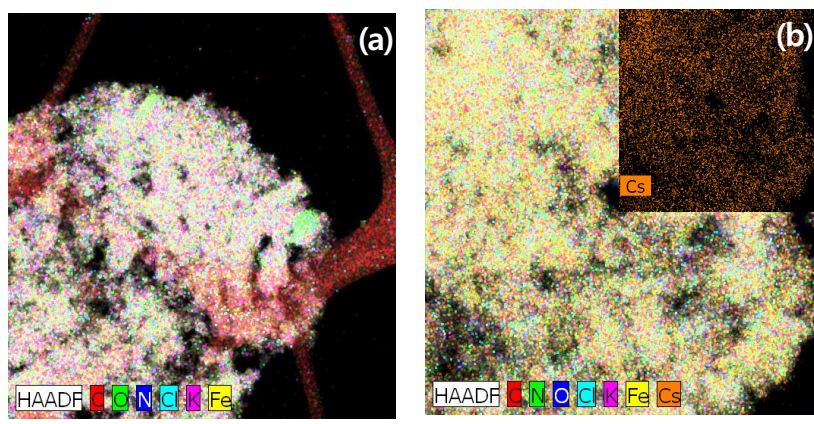

Fig. 2. Elemental mapping of PB-CGBC with FE-TEM (a) before and (b) after adsorption of cesium ions.
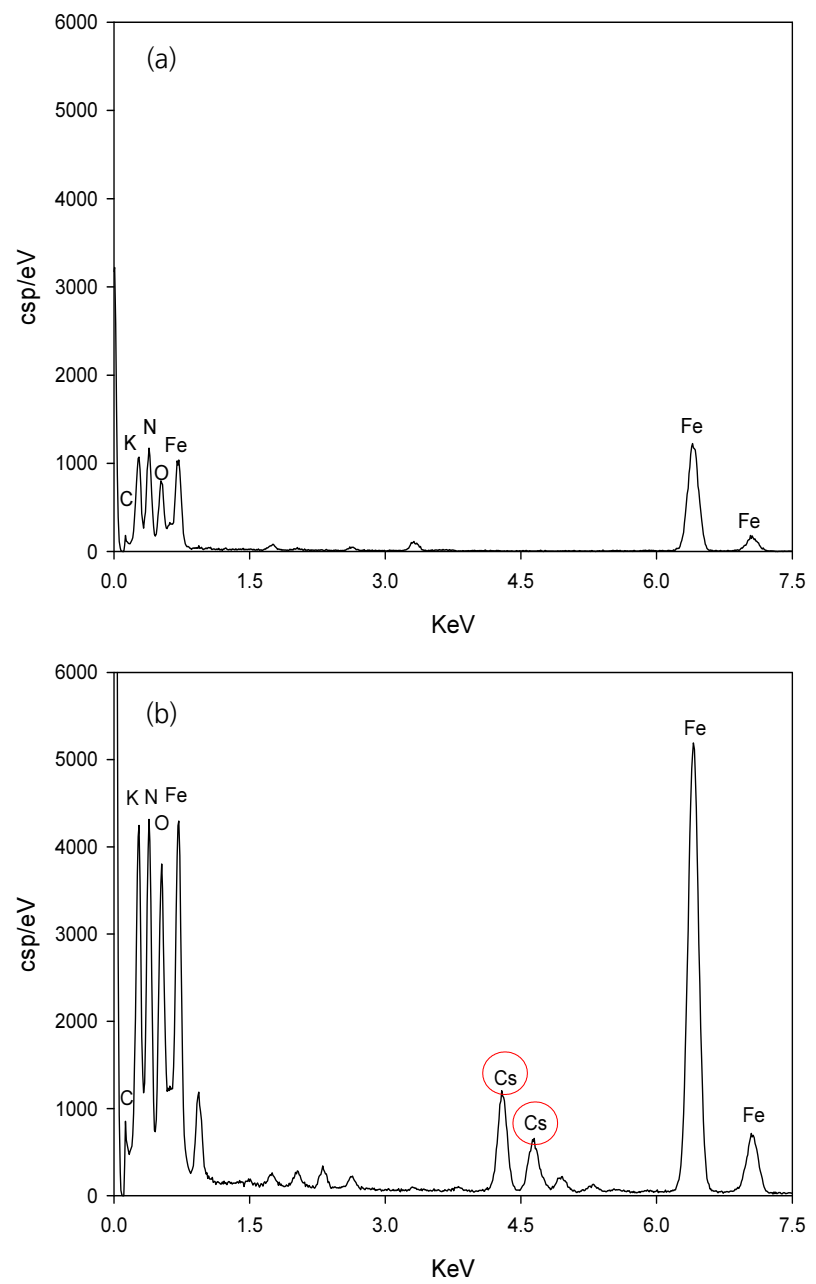

Fig. 3. TEM-EDX images of PB-CGBC (a) before and (b) after adsorption of cesium ions.

나타나는 주요 회절 피크가 나타났다. ${ }^{8,31)}$ Fig. 2는 FE-TEM에 기반한 원소 맵핑(Elemental mapping) 분석 결과로서, PB$\mathrm{CGBC}$ 에서 프러시안 블루의 $\mathrm{Fe}$ 성분이 관찰되었고(Fig.2(a)), 세슘 흡착 후 PB-CGBC에 세슘이 흡착되었음(Fig.2(b))을 확 인할 수 있었다. 마찬가지로 Fig.3의 EDX 결과에서도 흡착 전후에 $\mathrm{PB}-\mathrm{CGBC}$ 의 $\mathrm{Fe}$ 성분이 관찰되었고(Fig.3(a)), 흡착 

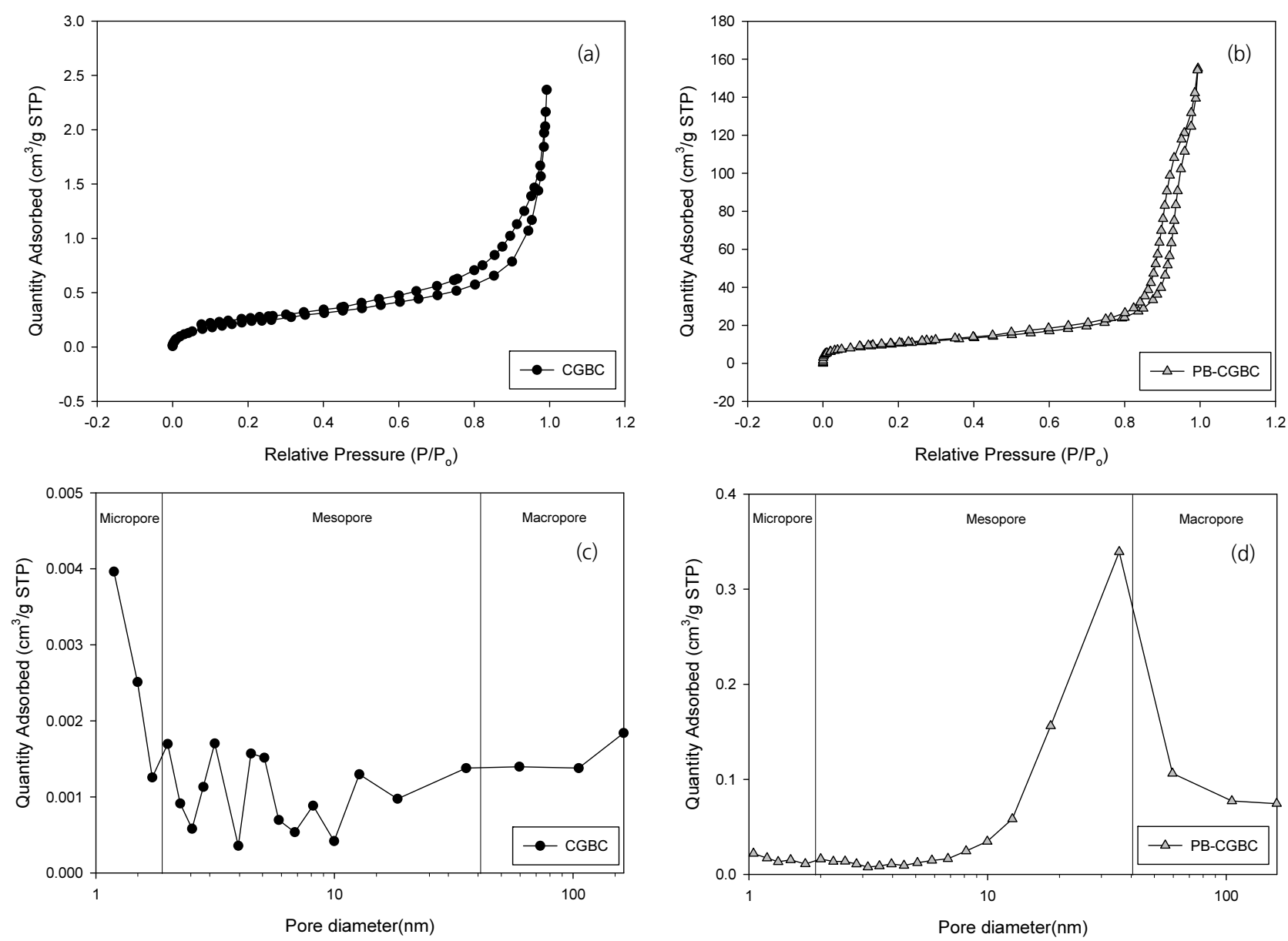

Fig. 4. Nitrogen adsorption/desorption isotherms of (a) CGBC and (b) PB-CGBC, and pore size distributions of (c) CGBC and (d) PB-CGBC.

Table 1. BET specific surface areas, average pore sizes, and pore volumes of CGBC and PB-CGBC.

\begin{tabular}{cccc} 
Sample & $\begin{array}{c}\text { Surface area } \\
\left(\mathrm{m}^{2} / \mathrm{g}\right)\end{array}$ & $\begin{array}{c}\text { Average pore size } \\
(\mathrm{nm})\end{array}$ & $\begin{array}{c}\text { Pore volume } \\
\left(\mathrm{cm}^{3} / \mathrm{g}\right)\end{array}$ \\
$\begin{array}{c}\text { CGBC } \\
\text { PB-CGBC }\end{array}$ & 3.00 & 9.694 & 0.0024 \\
\hline
\end{tabular}

후에 $\mathrm{PB}-\mathrm{CGBC}$ 의 세슘 성분이 관찰되어(Fig.3(b)) 같은 양상 을 띠었다. 따라서 흡착제 특성 분석을 통해 커피박 바이오차 표면에 프러시안 블루의 담지 여부와 $\mathrm{PB}-\mathrm{CGBC}$ 의 세슘 흡착 능력을 확인할 수 있었다.

Table 1은 $\mathrm{CGBC}$ 와 $\mathrm{PB}-\mathrm{CGBC}$ 의 $\mathrm{BET}$ 분석 결과를 나타낸 다. $\mathrm{CGBC}$ 표면과 기공 내부에 프러시안 블루 입자가 부착되 어 $\mathrm{PB}-\mathrm{CGBC}$ 의 비표면적과 기공 부피가 상대적으로 증가하 였음을 확인할 수 있다. $\mathrm{CGBC}$ 와 $\mathrm{PB}-\mathrm{CGBC}$ 의 질소 흡/탈착 등온선과 기공 크기 분포도는 Fig. 4에 나타내었다. IUPAC (International Union of Pure and Applied Chemistry) 기공 유형 분류에 따라, 질소 흡/탈착 등온선(Fig. 4(a)와 (b))은 $\mathrm{IV}$ 타입으로, 이 결과는 $\mathrm{CGBC}$ 와 $\mathrm{PB}-\mathrm{CGBC}$ 가 메조기공 (Mesopore, 2-50 nm)을 주로 가진 흡착제임을 보여준다. 또한,
Fig.4(c)로부터 CGBC가 메조기공뿐만 아니라 마이크로기공 (Micropore, $<2 \mathrm{~nm}$ )과 매크로기공(Macropore, $>50 \mathrm{~nm}$ )을 가 진 다공성 구조임을 예측할 수 있다. 이러한 $\mathrm{CGBC}$ 는 합성과 정을 통해 프러시안 블루 입자가 기공을 채우면서 메조기공을 주로 가진 PB-CGBC로 합성되었음을 알 수 있다(Fig.4(d)).

\section{2. $\mathrm{pH}$ 영향}

액체 방사성폐기물의 $\mathrm{pH}$ 는 대상 방사성핵종 제거에 상당 한 영향을 주는 영향인자로 알려져 있다. 본 연구에서 $\mathrm{pH}$ 실 험은 온도 $25^{\circ} \mathrm{C}$, 흡착제량 $2.5 \mathrm{~g} / \mathrm{L}$, 초기 세슘이온 농도 1 $\mathrm{mM}$ 로 하여 $\mathrm{pH}$ 4 10 범위에서 이루어졌다(Fig.5). pH가 4 에서 8까지 증가함에 따라 $\mathrm{PB}-\mathrm{CGBC}$ 의 흡착량은 증가하였 다. 이는 산성조건에서 보다 많은 수소이온이 세슘이온과 바 이오차 표면의 흡착 부위를 경쟁했기 때문이다. ${ }^{34)} \mathrm{pH}$ 를 8 이 상으로 증가시킬 때는 흡착률의 급격한 감소가 관찰되었다. 이는 알칼리 조건에서 철 이온과 수산화 이온과의 강력한 상 호작용을 인하여 $\mathrm{PB}-\mathrm{CGBC}$ 내의 $\mathrm{Fe}-\mathrm{CN}-\mathrm{Fe}$ 결합이 끊어 져 프러시안 블루의 구조가 파괴됨으로써 흡착능이 감소한 것으로 보인다. ${ }^{9.35)} \mathrm{pH}$ 변화에 따른 흡착량 변화뿐만 아니라 


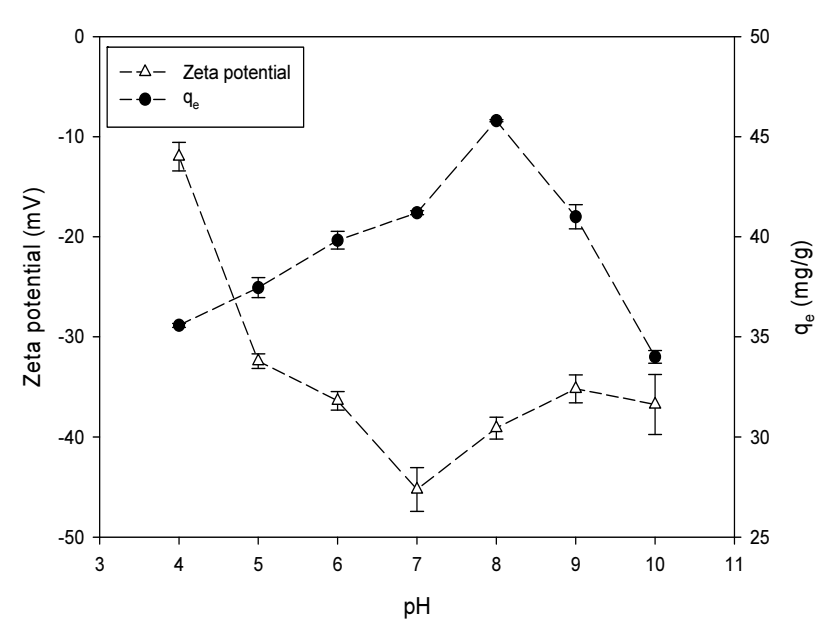

Fig. 5. Effect of pH on zeta potential and cesium adsorption onto PB-CGBC.

PB-CGBC의 제타전위 변화도 관찰하였다(Fig.5). $\mathrm{pH}$ 가 7에 서 4 로 감소할 때 제타전위는 증가하였는데, 이는 $\mathrm{pH}$ 가 감소 하면서 증가한 수소이온에 의해 PB-CGBC의 기능기 일부가 양자화(Protonation)되어 표면 음전하가 감소하였기 때문이 다. ${ }^{36)} \mathrm{pH}$ 값이 7 보다 클 때도 제타전위가 증가하는 것을 관 찰할 수 있었다.

\section{3. 온도 영향 및 열역학적 모델}

온도가 $\mathrm{PB}-\mathrm{CGBC}$ 의 세슘이온 흡착에 미치는 영향을 평가 하고자 $15,25,35^{\circ} \mathrm{C}$ 조건에서 초기 세슘 농도 $1 \mathrm{mM}, \mathrm{pH} 8$, 흡착제량 $2.5 \mathrm{~g} / \mathrm{L}$ 로 하여 실험을 수행하였다(Fig.6). 온도가 $15^{\circ} \mathrm{C}$ 에서 $35^{\circ} \mathrm{C}$ 로 증가함에 따라 흡착량은 $41.74 \mathrm{mg} / \mathrm{g}$ 에서 $32.28 \mathrm{mg} / \mathrm{g}$ 으로 감소하였다. 이는 PB-CGBC의 세슘이온 흡 착이 발열 반응이기 때문이다. 또한, $\mathrm{PB}-\mathrm{CGBC}$ 의 흡착 특성 에 대한 열역학적 해석을 위하여 Gibbs 자유에너지 변화량 $\left(\triangle G^{o}\right)$, 엔탈피 변화량 $\left(\triangle H^{o}\right)$, 엔트로피 변화량 $\left(\triangle S^{o}\right)$ 을 아래 식 (2)와 (3)으로부터 산출하였다.

$$
\begin{aligned}
& \triangle G^{o}=-R T \ln K_{c}=\Delta H^{o}-T \triangle S^{o} \\
& \ln K_{c}=\frac{\triangle S^{o}}{R}-\frac{\Delta H^{o}}{R T}
\end{aligned}
$$

여기서, $K_{c}\left(\mathrm{q}_{\mathrm{e}} / \mathrm{C}_{\mathrm{e}}\right)$ 는 흡착 평형상수이며, $R$ 은 기체상수 $(8.314 \mathrm{~J} / \mathrm{mol} \cdot \mathrm{K}), T$ 는 절대온도 $(\mathrm{K})$ 를 의미한다. $\ln K_{c}$ 와 $1 / \mathrm{T}$ 에 대한 직선식의 기울기와 절편으로부터 구한 $\triangle H$ 와 $\triangle S$ 은 각 각 $-33.36 \mathrm{~kJ} / \mathrm{mol}$ 과 $-60.0 \mathrm{~J} / \mathrm{mol} \cdot \mathrm{K}$ 이었다(Table 2). 온도가 15 , $25,35^{\circ} \mathrm{C}$ 로 증가할수록 $\triangle G^{o}$ 는 $-17.39,-16.48,-16.28 \mathrm{~kJ} / \mathrm{mol}$ 로 증가하였는데, 이는 온도가 증가하면 흡착의 자발성이 감 소한다는 것을 의미한다. 이러한 결과는 선행 연구된 프러 시안 블루 복합체의 세슘 흡착 양상과 유사하였다. ${ }^{35,37)}$ 음의 $\triangle H^{o}(-33.36 \mathrm{~kJ} / \mathrm{mol})$ 값은 $\mathrm{PB}-\mathrm{CGBC}$ 의 세슘 흡착이 발열반

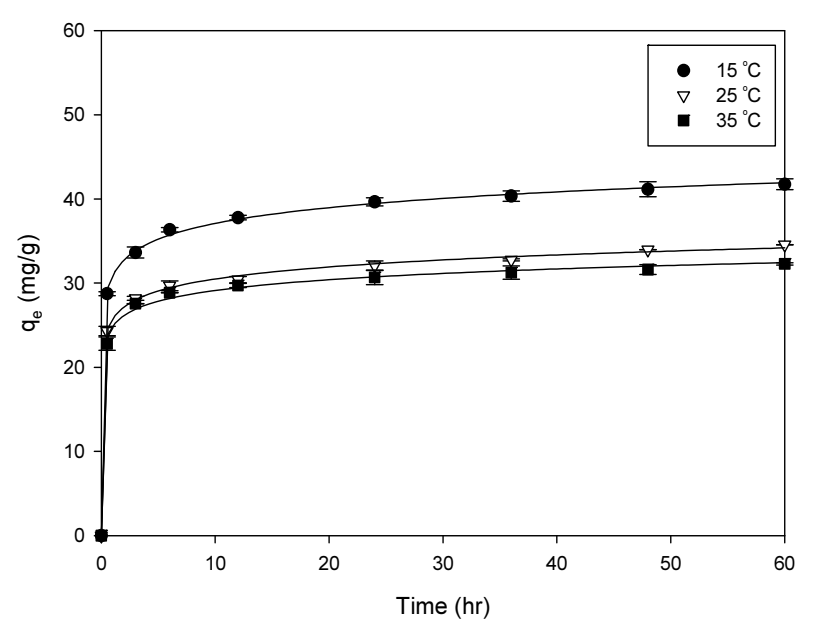

Fig. 6. Effect of temperature on the adsorption of cesium ions onto PB-CGBC.

Table 2. Thermodynamic model parameters at different

\begin{tabular}{|c|c|c|c|}
\hline \multirow{2}{*}{ Temperature $\left({ }^{\circ} \mathrm{C}\right)$} & \multicolumn{3}{|c|}{ Parameters } \\
\hline & $\Delta G^{\circ}(\mathrm{kJ} / \mathrm{mol})$ & $\Delta H^{\circ}(\mathrm{kJ} / \mathrm{mol})$ & $\Delta S^{\circ}(\mathrm{J} / \mathrm{mol} \cdot \mathrm{K})$ \\
\hline 15 & -17.39 & & \\
\hline 25 & -16.48 & -33.36 & -60.0 \\
\hline 35 & -16.28 & & \\
\hline
\end{tabular}
temperatures.

응임을 열역학적으로 뒷받침하며, 저온에서 반응이 더 잘 일 어남을 의미한다. 그리고 $\triangle H^{o}$ 의 절대값이 $25 \mathrm{~kJ} / \mathrm{mol}$ 보다 큰 경우는 화학적 흡착이 강함을 나타내므로, $\mathrm{PB}-\mathrm{CGBC}$ 의 세슘 흡착은 화학적 흡착이 우세함을 유추할 수 있다. ${ }^{38,39)}$ 또한, 음의 $\triangle S^{o}(-60.0 \mathrm{~J} / \mathrm{mol} \cdot \mathrm{K})$ 값은 $\mathrm{PB}-\mathrm{CGBC}$ 에 세슘이온이 흡 착되면서 흡착제와 용액의 계면 사이에서 무질서도가 감소하 였다는 것을 의미한다.

\section{4. 동력학적 모델}

$\mathrm{PB}-\mathrm{CGBC}$ 에 대한 세슘이온 흡착의 동력학적 특성을 조사 하기 위하여, 유사 1차 속도식(Pseudo-first-order model), 유사 2차 속도식(Pseudo-second-order model) 및 Elovich 속도식 모 델에 적용하였으며, 관련된 흡착 반응속도 모델은 아래 식 (4), (5) 및 (6)과 같다.

$$
\begin{aligned}
& \ln \left(q_{e}-q_{t}\right)=\ln q_{e}-k_{1} t \\
& \frac{t}{q_{t}}=\frac{1}{k_{2} q_{e}^{2}}+\frac{1}{q_{e}} t \\
& q_{t}=\frac{1}{\beta} \ln (\alpha \beta)+\frac{1}{\beta} \ln t
\end{aligned}
$$

여기서, $q_{e}(\mathrm{mg} / \mathrm{g})$ 는 평형 흡착량, $q_{t}(\mathrm{mg} / \mathrm{g})$ 는 시간 $t$ 에서의 흡착량, $k_{1}\left(\mathrm{hr}^{-1}\right)$ 은 Lagergren 일차 속도상수, $k_{2}(\mathrm{~g} / \mathrm{mg} \cdot \mathrm{hr})$ 는 유사 이차 속도상수, $\alpha(\mathrm{g} / \mathrm{mg} \cdot \mathrm{hr})$ 는 초기 흡착속도, $\beta(\mathrm{mg} /$ 
Table 3. Kinetic model parameters at different temperatures.

\begin{tabular}{|c|c|c|c|c|c|c|c|c|c|c|}
\hline \multirow[b]{2}{*}{$\begin{array}{c}\text { Temperature } \\
\left({ }^{\circ} \mathrm{C}\right)\end{array}$} & \multirow[b]{2}{*}{$\begin{array}{c}q_{e, \exp } \\
(\mathrm{mg} / \mathrm{g})\end{array}$} & \multicolumn{3}{|c|}{ Pseudo-first-order } & \multicolumn{3}{|c|}{ Pseudo-second-order } & \multicolumn{3}{|c|}{ Elovich } \\
\hline & & $\begin{array}{c}q_{e, c a l} \\
(\mathrm{mg} / \mathrm{g})\end{array}$ & $\begin{array}{c}k_{1} \\
\left(h^{-1}\right)\end{array}$ & $R^{2}$ & $\begin{array}{c}q_{e, c a l} \\
(\mathrm{mg} / \mathrm{g})\end{array}$ & $\begin{array}{c}k_{2} \\
(\mathrm{~g} / \mathrm{mg} \cdot \mathrm{hr})\end{array}$ & $R^{2}$ & $\begin{array}{c}a \times 10^{6} \\
(\mathrm{mg} / \mathrm{g} \cdot \mathrm{hr})\end{array}$ & $\begin{array}{c}\beta \\
(g / m g)\end{array}$ & $R^{2}$ \\
\hline 15 & 41.7 & 38.67 & 2.71 & 0.958 & 39.66 & 0.11 & 0.978 & 0.25 & 0.37 & 0.999 \\
\hline 25 & 34.6 & 31.66 & 2.91 & 0.960 & 32.37 & 0.16 & 0.976 & 0.54 & 0.48 & 0.999 \\
\hline 35 & 32.5 & 30.29 & 2.79 & 0.977 & 30.94 & 0.16 & 0.990 & 1.30 & 0.54 & 0.997 \\
\hline
\end{tabular}

$\mathrm{g} \cdot \mathrm{hr}$ )는 화학흡착에 대한 Elovich 상수를 나타낸다. 서로 다 른 온도에서 진행한 $\mathrm{PB}-\mathrm{CGBC}$ 에 대한 세슘이온 흡착 실험결 과에 각 동력학적 모델들을 적용하였다(Table 3). Elovich 모 델의 $\mathrm{R}^{2}$ 값은 0.99 이상으로 유사 1 차 및 2 차 반응속도식 모델 보다 실험값과 예측값의 상관관계가 높은 것으로 나타났다. 따라서, 흡착반응의 속도결정 단계가 세슘이온과 $\mathrm{PB}-\mathrm{CGBC}$ 표면 반응기의 화학적 반응임을 알 수 있다. 특히, 15,25 , $35^{\circ} \mathrm{C}$ 의 온도에서 $\alpha$ 값이 $\beta$ 값보다 매우 큰 것을 확인할 수 있는데, 이는 흡착 반응이 비가역적임을 의미한다. ${ }^{40)}$

입자내 확산 메카니즘을 확인하기 위해서, Weber-Morris 입 자내 확산 모델식 (7)을 적용하였다.

$$
q_{t}=k_{i} t^{0.5}+C
$$

여기서, $k_{i}\left(\mathrm{mg} / \mathrm{g} \cdot \mathrm{h}^{0.5}\right)$ 는 입자내 확산속도상수, $C$ 는 절편을 나타낸다. 입자내 확산식에 $15,25,35^{\circ} \mathrm{C}$ 의 온도에서의 흡착 데이터를 적용하였을 때, 기울기가 다른 두 개의 직선으로 나 타났다(Fig.7). 초기 직선식 단계는 세슘이온이 용액에서 흡착 제 외부표면으로 확산되면서 빠르게 흡착반응이 진행된 외부 표면 흡착단계에 해당되며, 두 번째 단계는 입자내 세공확산이 점진적으로 이루어지는 흡착단계로서 천천히 최종평형에 도 달하는 단계이다. 각기 다른 온도에서 직선의 기울기로부터 얻은 입자내 확산속도상수를 Table 4에 나타내었다. 첫 번째 직선구간에 해당하는 외부물질전달 상수값 $\left(k_{i 1}\right)$ 들이 두 번째 직선 구간으로부터 얻어진 입자내 확산상수값 $\left(k_{i 2}\right)$ 들 보다 횔 씬 큰 것을 확인할 수 있으며, 이로부터 입자내 세공확산에 의한 흡착단계가 율속단계인 것을 알 수 있었다. 세공내 입자 간 확산에 해당하는 두 번째 직선 구간의 절편 값들은 확산경 계층의 두께에 대한 정보를 제공한다. 온도가 증가함에 따라 경계층 두께가 감소하는 것을 확인할 수 있는데, 이는 높은 온도에서 증가된 열적 에너지에 의한 무작위 운동이 증가함에 따라 표면 확산이 보다 더 중요해진다는 것을 나타낸다.

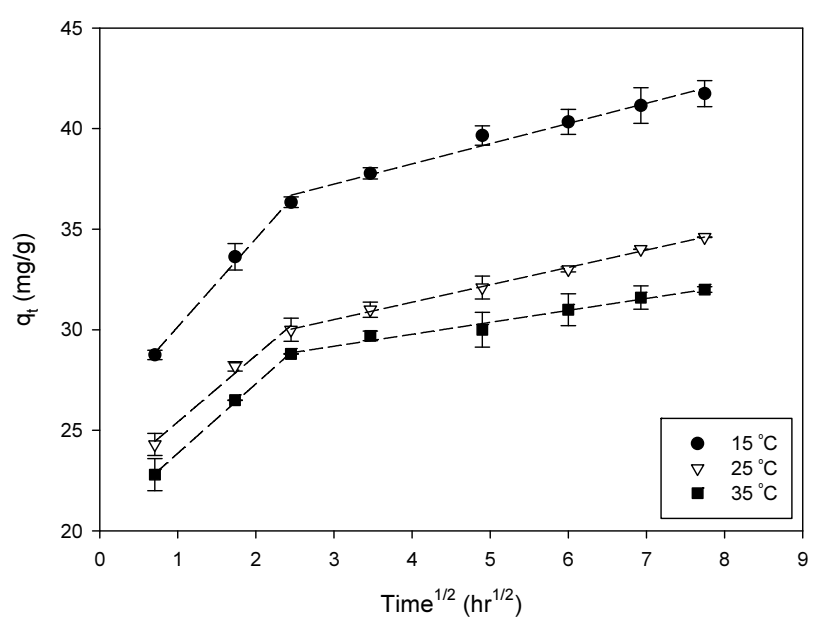

Fig. 7. Intraparticle diffusion models for cesium adsorption by PB-CGBC.

\section{5. 반응 시간 및 초기 농도의 영향}

반응 시간과 초기 농도 변화에 따른 PB-CGBC에 대한 세슘 흡착 결과를 Fig.8에 나타내었다. 실험은 초기 세슘 농도 1 $10 \mathrm{mM}, \mathrm{pH} 8$, 온도 $15^{\circ} \mathrm{C}$, 흡착제량 $2.5 \mathrm{~g} / \mathrm{L}$ 조건에서 72 시간 까지 진행하였다. 모든 농도에서 24시간까지 흡착량이 빠르게 증가하는 경향을 보이다가 24시간 이후부터 평형에 도달하였 다. 이는 반응 초기에 세슘이온이 흡착할 수 있는 반응기가 $\mathrm{PB}-\mathrm{CGBC}$ 표면에 충분히 존재하다가 일정 시간이 지난 후 포화되었음을 의미한다. 또한, 농도가 $1 \mathrm{~m} \mathrm{M}$ 에서 $10 \mathrm{mM}$ 로 증가하면서 흡착량이 $41.7 \mathrm{mg} / \mathrm{g}$ 에서 $103.0 \mathrm{mg} / \mathrm{g}$ 으로 증가하 였는데 이는 흡착 구동력인 농도차의 증가 때문이다.

\section{6. 등온흡착식}

흡착공정에서 등온흡착 모델에 대한 예측은 공정의 설계 및 적용에 중요한 결정사항이다. 따라서 영향인자 실험을 기 반으로 하여 초기 세슘 농도 $1 \sim 40 \mathrm{mM}$ 에서 $\mathrm{pH} 8$, 온도 $15^{\circ} \mathrm{C}$,

Table 4. Intraparticle diffusion model rate constants at different temperatures.

\begin{tabular}{|c|c|c|c|c|c|c|}
\hline \multirow{2}{*}{ Temperature $\left({ }^{\circ} \mathrm{C}\right)$} & \multicolumn{3}{|c|}{ First linear portion } & \multicolumn{3}{|c|}{ Second linear portion } \\
\hline & $k_{i 1}$ & $C$ & $R^{2}$ & $k_{i 2}$ & $C$ & $R^{2}$ \\
\hline 15 & 4.38 & 25.76 & 0.992 & 1.00 & 34.23 & 0.973 \\
\hline 25 & 3.31 & 22.11 & 0.976 & 0.86 & 27.91 & 0.997 \\
\hline 35 & 3.45 & 20.40 & 0.998 & 0.59 & 27.40 & 0.972 \\
\hline
\end{tabular}




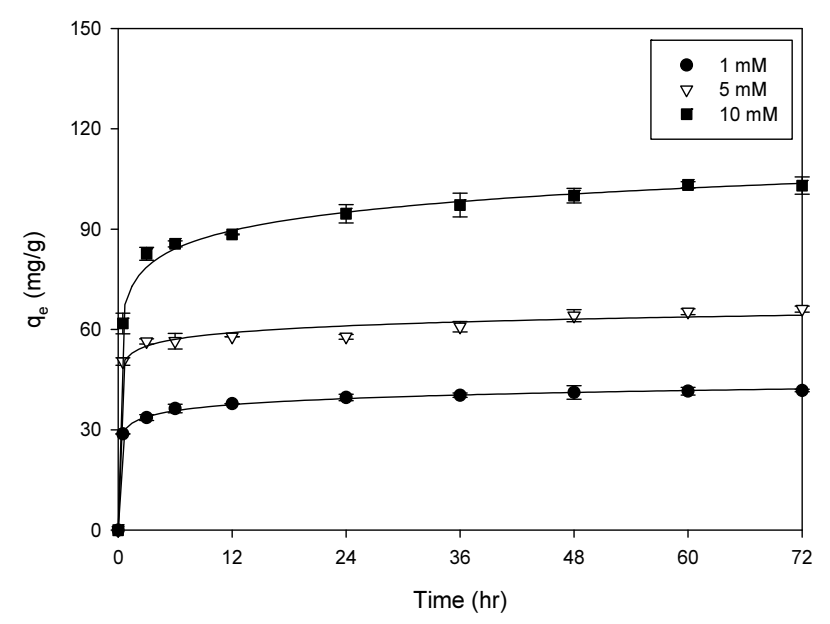

Fig. 8. Effect of initial cesium concentration and contact time on cesium adsorption onto PB-CGBC.

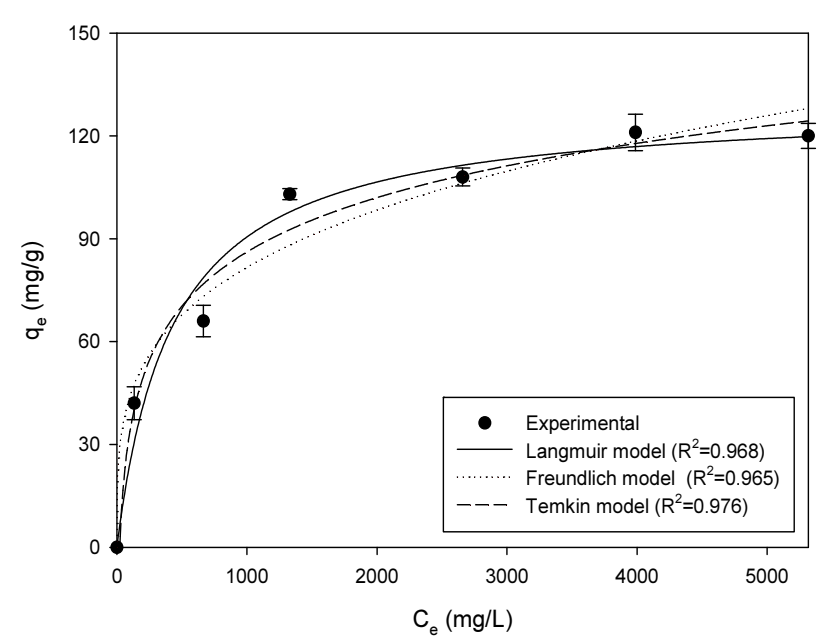

Fig. 9. Adsorption isotherm results.

흡착제량 $2.5 \mathrm{~g} / \mathrm{L}$ 조건에서 등온흡착 실험을 진행하였다. 실험 결과는 아래 제시된 등온흡착모델인 Langmuir 모델, Freundlich 모델 및 Temkin 모델 관련한 아래 식 (8), (9) 및 (10)를 적용하였다(Fig. 9).
Table 5. Isotherm parameters for cesium adsorption onto the PB-CGBC.

\begin{tabular}{cccc} 
Models & Parameters & Value & $R^{2}$ \\
Langmuir & $K_{L}(\mathrm{~L} / \mathrm{mg})$ & 0.31 & \\
& $q_{\text {max }}(\mathrm{mg} / \mathrm{g})$ & 129.57 & 0.968 \\
Freundlich & $K_{F}(\mathrm{mg} / \mathrm{g})(\mathrm{L} / \mathrm{mg})^{1 / n}$ & 47.29 & \\
& $n$ & 3.70 & 0.965 \\
Temkin & $A_{r}(\mathrm{~L} / \mathrm{g})$ & 5.74 & \\
& $b$ & 104.74 & 0.976 \\
\hline
\end{tabular}

$q_{e}=\frac{q_{\max } K_{L} C_{e}}{1+K_{L} C_{e}}$

$q_{e}=K_{F} C_{e}^{\frac{1}{n}}$

$$
q_{e}=\frac{R T}{b \ln \left(A_{r} C_{e}\right)}
$$

여기서, $q_{\max }(\mathrm{mg} / \mathrm{g})$ 는 최대흡착량, $K_{L}(\mathrm{~L} / \mathrm{mg})$ 는 Langmuir 등온 상수, $K_{F}(\mathrm{~L} / \mathrm{g})$ 는 Freundlich 등온 상수, $A_{r}(\mathrm{~L} / \mathrm{g})$ 는 Temkin 등온 상수, $n$ 은 Freundlich 지수, $b$ 는 Temkin 상수를 나타낸다. Table5에 나타나 있듯이 PB-CGBC에 대한 세슘 이온의 흡착은 Temkin 모델 $\left(\mathrm{R}^{2}=0.976\right)$, Langmuir 모델 $\left(\mathrm{R}^{2}=0.968\right)$, Freundlich 모델 $\left(\mathrm{R}^{2}=0.965\right)$ 순으로 상관계수 $\left(\mathrm{R}^{2}\right)$ 가 큰 것으로 나타났다. 초기 세슘 농도 $40 \mathrm{mM}$ 으로부터 얻어진 PB-CGBC의 최대흡착량은 $120.00 \mathrm{mg} / \mathrm{g}$ 으로 나타났는데 이는 Langmuir 모델에서 구한 이론적인 최대 흡착량 $129.57 \mathrm{mg} / \mathrm{g}$ 에 근접한 값이다. 본 연구에서 얻어진 $\mathrm{PB}-\mathrm{CGBC}$ 의 최대 흡 착량 $\left(q_{\max }\right)$ 을 현재까지 연구된 프러시안 블루 기반 흡착제와 생물흡착제의 최대흡착량과 비교하였을 때, 기존에 보고된 흡착제보다 PB-CGBC가 보다 더 우수한 세슘이온 흡착성능 을 가지고 있음을 확인할 수 있었다(Table 6).

Langmuir 모델의 $K_{L}$ 값에 기반한 무차원 분리계수 $\left(R_{L}\right)$ 를 다음 식 (11)에 의해 계산하여 흡착처리의 적합 여부를 판단하

Table 6. Comparative study of cesium adsorption considering maximum adsorption capacity.

\begin{tabular}{|c|c|c|c|c|}
\hline Adsorbent & $\mathrm{pH}$ & $\mathrm{T}\left({ }^{\circ} \mathrm{C}\right)$ & $\begin{array}{c}q_{\max } \\
(\mathrm{mg} / \mathrm{g})\end{array}$ & Ref. \\
\hline Montmorillonite-prussian blue hybrid & $6.5-7.0$ & 20 & 57.47 & 1 \\
\hline Bamboo charcoal & - & - & 63.40 & 2 \\
\hline Immobilized nickel hexacyanoferrate on activated carbons & - & 27 & 31.25 & 41 \\
\hline Prussian blue-coated magnetic nanoparticle & - & - & 96.00 & 42 \\
\hline $\begin{array}{l}\text { Prussian blue-functionalized } \\
\text { magnetic nanoclusters }\end{array}$ & - & - & 45.87 & 43 \\
\hline Iron based nanoparticles-zeolite composites & 6.0 & 25 & 77.51 & 44 \\
\hline Bentonite-chitosan beads & - & 25 & 57.10 & 45 \\
\hline Nitric acid-modified bamboo charcoal & - & 20 & 45.87 & 46 \\
\hline PB-CGBC & 8.0 & 15 & 129.57 & This study \\
\hline
\end{tabular}


였다.

$$
R_{L}=\frac{1}{1+K_{L} C_{o}}
$$

여기서, $R_{L}>1$ 이면 흡착이 일어나지 않고, $R_{L}=1$ 이면 흡착은 선형적으로 일어나고, $0<R_{L}<1$ 이면 효율적인 흡착이 가능 하며, $R_{L}=0$ 이면 흡착은 비가역적이다. 본 실험에서 얻은 $\mathrm{PB}-\mathrm{CGBC}$ 의 무차원 분리계수는 모든 온도에서 $R_{L}=0.07$ 0.77 로 모두 0 과 1 사이에 존재하였기에 PB-CGBC에 의한 세 슘이온의 흡착처리가 효과적인 공정이라는 것을 확인할 수 있 었다.

\section{4. 결론}

본 연구에서는 프러시안 블루로 담지된 커피박 바이오차 (PB-CGBC)를 합성하여 액체 방사성폐기물 내의 세슘이온 을 흡착 반응에 의해서 제거하고자 하였다. FT-IR, XRD, FE-TEM, BET 및 제타전위 특성 분석 결과로부터, PB-CGBC 표면에 풍부한 기능기 그룹이 존재하고 독특한 표면 구조를 가지고 있음을 확인할 수 있었다. $\mathrm{PB}-\mathrm{CGBC}$ 에 의한 세슘이온 흡착량은 $\mathrm{pH}$ 를 4 에서 8 까지 증가시켰을 때, 흡착량은 증가하 였으나 $\mathrm{pH}$ 값이 9 이상일 때는 프러시안 블루의 $\mathrm{Fe}-\mathrm{CN}-\mathrm{Fe}$ 결합이 끊어져 흡착량이 감소하였다. $\mathrm{PB}-\mathrm{CGBC}$ 에 대한 세 슘이온 흡착은 온도가 증가함에 따라 Gibbs 자유에너지가 증가하였으며, 이는 온도가 증가할수록 흡착공정의 자발성 이 감소함을 나타낸다. 또한, $\triangle H^{o}$ 가 음의 값을 가지므로 $\mathrm{PB}-\mathrm{CGBC}$ 의 세슘이온 흡착반응이 발열반응임을 열역학적으 로 뒷받침해 주었다. 동력학적 실험결과는 Elovich 모델이 유 사 일차 및 이차 반응속도식보다 일치도가 높았다. 입자내 확 산식으로부터 $\mathrm{PB}-\mathrm{CGBC}$ 입자내 세공확산에 의한 흡착단계 가 흡착반응 율속단계인 것을 알 수 있었다. 또한, 등온흡착 실험 결과로부터 Temkin 모델이 가장 높은 일치도를 나타내 었으며, $\mathrm{PB}-\mathrm{CGBC}$ 의 최대흡착량은 선행 연구된 프러시안 블 루 기반의 흡착제보다 우수하였다. 이러한 실험결과로부터 본 연구에서 합성된 PB-CGBC는 액체 방사성폐기물 내의 세 슘이온을 효과적으로 제거할 수 있는 흡착제임을 확인할 수 있었다.

\section{Acknowledgement}

본 연구는 2018학년도 경북대학교 연구년 교수 연구비에 의하여 연구되었습니다.

\section{References}

1. H. A. Alamudy, K. Cho, Selective adsorption of cesium from an aqueous solution by a montmorillonite-prussian blue hybrid, Chem. Eng. J., 349, 595-602(2018).

2. J. P. Ahn, M. H. Lee, Sorption efficiency of the bamboo charcoal to remove the cesium in the contaminated water system, Econ. Environ. Geol., 51(2), 87-97(2018).

3. J. Wang, S. Zhuang, Removal of cesium ions from aqueous solutions using various separation technologies, Rev. Environ. Sci. Biotechnol., 18, 231-269(2019).

4. J. H. Lee, J. E. Kang, W. S. Kim, Removal of radioactive cesium in secondary wastewater after soil-washing process, J. Korean Soc. Environ. Eng., 42(8), 405-413(2020).

5. J. S. Jang, D. S. Lee, Enhanced adsorption of cesium on PVA-alginate encapsulated prussian blue-graphene oxide hydrogel beads in a fixed-bed column system, Bioresour. Technol., 218, 294-300(2016).

6. H. Yang, L. Sun, J. Zhai, H. Li, Y. Zhao, H. Yu, In situ controllable synthesis of magnetic prussian blue/graphene oxide nanocomposites for removal of radioactive cesium in water, J. Mater. Chem. A, 2, 326-332(2014).

7. X. Liu, G. R. Chen, D. J. Lee, T. Kawamoto, H. Tanaka, M. L. Chen, Y. K. Luo, Adsorption removal of cesium from drinking waters: a mini review on use of biosorbents and other adsorbents, Bioresour. Technol., 160, 142-149(2014).

8. S. C. Jang, Y. Haldorai, G. W. Lee, S. K. Hwang, Y. K. Han, C. Roh, Y. S. Huh, Porous three-dimensional graphene foam/prussian blue composite for efficient removal of radioactive ${ }^{137} \mathrm{Cs}$, Sci. Rep., 5, 17510(2015).

9. A. A. Kadam, J. Jang, D. S. Lee, Facile synthesis of pectin-stabilized magnetic graphene oxide prussian blue nanocomposites for selective cesium removal from aqueous solution, Bioresour. Technol., 216, 391-398(2016).

10. S. Kim, S. W. Kang, B. S. Kim, D. M. Oh, Y. S. Kim, Y. S. Chung, Y. H. Hwang, Synthesis of adsorbent fixed with prussian blue based by illite, J. Korean Soc. Environ. Eng., 41(1), 24-30(2019).

11. X. F. Tan, Y. G. Liu, Y. L. Gu, Y. Xu, G. M. Zeng, X. J. Hu, S. B. Liu, X. Wang, S. M. Liu, J. Li, Biochar-based nanocomposites for the decontamination of wastewater: a review, Bioresour. Technol., 212, 318-333(2016).

12. H. S. Oh, J. S. Chang, Enhancement of the congo red adsorption capacity of biochars by surface modification with $\mathrm{MgCl}_{2}$ pretreatment, J. Korean Soc. Environ. Eng., 42(10), 472-481(2020).

13. J. S. Jang, W. Mirana, S. D. Divine, M. Nawaz, A. Shahzad, S. H. Woo, D. S. Lee, Rice straw-based biochar beads for the removal of radioactive strontium from aqueous solution, Sci. Total Environ., 615, 698-707(2018).

14. S. Khandaker, T. Kuba, S. Kamida, Y. Uchikawa, Adsorption of cesium from aqueous solution by raw and concentrated nitric acid-modified bamboo charcoal, J. Environ. Chem. Eng., 5(2), 1456-1464(2017).

15. Q. Tao, X. Zhang, D. Huang, G. Huang, J. Fan, H. Peng, 
Y. Dai, K. Prabaharan, Copper hexacyanoferrate nanoparticle decorated biochar produced from pomelo peel for cesium removal from aqueous solution, J. Radioanal. Nucl. Chem., 322, 791-799(2019).

16. T. Asada, N. Sato, T. Ozeki, A. Ito, T. Takase, Radioactive Cs removal from aqueous solutions by biochar Immobilized potassium nickel hexacyanoferrate prepared using ball mill, Int. J. Environ. Res., 15, 447-455(2021).

17. M. Piplšša, S. Ballová, V. Frišták, L. Ďuriška, M. Horník, Š. Demčák, M. Holub, G. Soja, Potassium nickel(II) hexacyanoferrate(III)-functionalized biochar for selective separation of radiocesium from liquid wastes, J. Radiat. Res. Appl. Sci., 13(1), 343-355(2020).

18. V. Boonamnuayvitaya, C. Chaiya, W. Tanthapanichakoon, S. Jarudilokkul, Removal of heavy metals by adsorbent prepared from pyrolyzed coffee residues and clay, Sep. Purif. Technol., 35(1), 11-22(2004).

19. W. T. Tsai, S. C. Liu, C. H. Hsieh, Preparation and fuel properties of biochars from the pyrolysis of exhausted coffee residue, J. Anal. Appl. Pyrolysis, 93, 63-67(2012).

20. J. G. Shin, K. R. Ha, K. M. Chon, Removal efficiency of pharmaceuticals using coffee residues biochar activated with zinc chloride and powdered activated carbon, J. Korean Soc. Environ. Eng., 41(10), 515-523(2019).

21. D. W. Cho, K. Yoon, E. E. Kwon, J. K. Biswas, H. Song, Fabrication of magnetic biochar as a treatment medium for $\mathrm{As}(\mathrm{V})$ via pyrolysis of $\mathrm{FeCl}_{3}$ pretreated spent coffee ground, Environ. Pollut., 229, 942-949(2017).

22. K. W. Jung, B. H. Choi, M. J. Hwang, T. U. Jeong, K. H. Ahn, Fabrication of granular activated carbons derived from spent coffee grounds by entrapment in calcium alginate beads for adsorption of acid orange 7 and methylene blue, Bioresour. Technol., 219, 185-195(2016).

23. M. H, Park. G. R, Lee. H. S. Park, S. J. Jeong, J. Y. Kim, Adsorption of lead and cadmium from wastewater utilizing nano zero valent iron supported by coffee ground, J. Korean Soc. Environ. Eng., 40(2), 82-90(2018).

24. B. M. Kim, C. H. Kang, J. K. Na, H. J. Jung, K. M. Ko, Y. Y. Chang, J. K. Yang, J. A. Jung, J. H. Lim, W. H. Kim, $\mathrm{Cu}$ and $\mathrm{Cd}$ sorption of the biochar derived from coffee sludge, J. Soil Groundw. Environ., 17(2), 47-53(2012).

25. J. H. Park, H. C. Kim, Y. J. Kim, S. H. Kim, D. C. Seo, Adsorption characteristics of copper using biochar derived from exhausted coffee residue, Korean J. Environ. Agric., 36(1), 22-28(2017).

26. M. H. Rodiguez, J. Yperman, R. Carleer, J. Maggen, D. Dadi, G. Gryglewicz, B. Van Der Bruggen, J. F. Hernández, A. O. Calvis, Adsorption of $\mathrm{Ni}(\mathrm{II})$ on spent coffee and coffee husk based activated carbon, J. Environ. Chem. Eng., 6(1), 1161-1170(2018).

27. R. Lafi, I. Montasser, A. Hafiane, Adsorption of congo red dye from aqueous solutions by prepared activated carbon with oxygen-containing functional groups and its regeneration, Adsorpt. Sci. Technol., 37(1-2), 160-181(2019).

28. S. H. Liu, Y. Y. Huang, Valorization of coffee grounds to biochar-derived adsorbents for $\mathrm{CO}_{2}$ adsorption, J. Clean. Prod., 175, 354-360(2018).

29. X. Li, V. Strezov, T. Kan, Energy recovery potential analysis of spent coffee grounds pyrolysis products, J. Anal. Appl. Pyrolysis., 110, 79-87(2014).

30. V. T. Nguyen, T. B. Nguyen, C. W. Chen, C. M. Hung, T. D. H. Vo, J. H. Chang, C. D. Dong, Influence of pyrolysis temperature on polycyclic aromatic hydrocarbons production and tetracycline adsorption behavior of biochar derived from spent coffee ground, Bioresour. Technol., 284, 197-203(2019).

31. L. Chang, S. Chang, W. Chen, W. Han, Z. Li, Z. Zhang, Y. Dai, D. Chen, Facile one-pot synthesis of magnetic prussian blue core/shell nanoparticles for radioactive cesium removal, RSC Adv., 6(98), 96223-96228(2016).

32. X. Liu, J. Sun, S. Duan, Y. Wang, T. Hayat, A. Alsaedi, C. Wang, J. Li, A valuable biochar from poplar catkins with high adsorption capacity for both organic pollutants and inorganic heavy metal ions, Sci. Rep., 7, 10033(2017).

33. P. Lahijani, M. Mohammadi, A. R. Mohamed, Metal incorporated biochar as a potential adsorbent for high capacity $\mathrm{CO}_{2}$ capture at ambient condition, J. $\mathrm{CO}_{2}$ Util., 26, 281-293(2018).

34. O. A. A. Moamen, H. A. Ibrahim, N. Abdelmonem, I. M. Ismail, Thermodynamic analysis for the sorptive removal of cesium and strontium ions onto synthesized magnetic nano zeolite, Microporous Mesoporous Mater., 223, 187-195(2016).

35. J. Jang, D. S. Lee, Magnetic prussian blue nanocomposites for effective cesium removal from aqueous solution, Ind. Eng. Chem. Res., 55(13), 3852-3860(2016).

36. M. Taheran, M. Naghdi, S. K. Brar, E. J. Knystautas, M. Verma, A. A. Ramirez, R. Y. Surampalli, J. R. Valero, Adsorption study of environmentally relevant concentrations of chlortetracycline on pinewood biochar, Sci. Total Environ., 571, 772-777(2016).

37. A. A. Nayl, I. M. Ahmed, H. F. Aly, M. F. Attallah, Selective sorption of ${ }^{134} \mathrm{Cs}$ and ${ }^{60} \mathrm{Co}$ radioisotopes using synthetic nanocopper ferrocyanide- $\mathrm{SiO}_{2}$ materials, Sep. Purif. Technol., 234, 116060(2020).

38. T. Wang, M. Li, W. Yeh, Y. Wei, S. Teng, Removal of cesium ions from aqueous solution by adsorption onto local Taiwan laterite, J. Hazard. Mater., 160, 638-642(2008).

39. S. C. Tsai, T. H. Wang, M. H. Li, Y. Y. Wei, S. P. Teng, Cesium adsorption and distribution onto crushed granite under different physicochemical conditions, J. Hazard. Mater., 161(2-3), 854-861(2009).

40. O. Pezoti, A. L. Cazetta, K. C. Bedin, L. S. Souza, A. C. Martins, T. L. Silva, O. O. Santos Júnior, J. V. Visentainer, V. C. Almeida, $\mathrm{NaOH}$-activated carbon of high surface area produced from guava seeds as a high-efficiency adsorbent for amoxicillin removal: kinetic, isotherm and thermodynamic studies, Chem. Eng. J., 288, 778-788(2016).

41. Lalhmunsiama, C. Lalhriatpuia, D. Tiwari, S. M. Lee, Immobilized nickel hexacyanoferrate on activated carbons for efficient attenuation of radio toxic $\mathrm{Cs}(\mathrm{I})$ from aqueous solutions, Appl. Surf. Sci., 321, 275-282(2014). 
42. C. Thammawong, P. Opaprakasit, P. Tangboriboonrat, P. Sreearunothai, Prussian blue-coated magnetic nanoparticles for removal of cesium from contaminated environment, J. Nanoparticle Res., 15, 1689(2013).

43. H. M. Yang, S. C. Jang, S. B. Hong, K. W. Lee, C. Roh, Y. S. Huh, B. K. Seo, Prussian blue-functionalized magnetic nanoclusters for the removal of radioactive cesium from water, J. Alloys Compd., 657, 387-393(2016).

44. O. Eljamal, T. Shubair, A. Tahara, Y. Sugihara, N. Matsunaga, Iron based nanoparticles-zeolite composites for the removal of cesium from aqueous solutions, J. Mol. Liq., 277, 613-623(2019).

45. K. Wang, H. Ma, S. Pu, C. Yan, M. Wang, J. Yu, X. Wang, W. Chu, A. Zinchenko, Hybrid porous magnetic bentonite-chitosan beads for selective removal of radioactive cesium in water, J. Hazard. Mater., 362, 160-169(2019).

46. S. Khandaker, T. Kuba, S. Kamida, Y. Uchikawa, Adsorption of cesium from aqueous solution by raw and concentrated nitric acid-modified bamboo charcoal, J. Environ. Chem. Eng., 5(2), 1456-1464(2017).

\section{Declaration of Competing Interest}

The authors declare that they have no known competing financial interests or personal relationships that could have appeared to influence the work reported in this paper.

\section{Authors and Contribution Statement}

\section{Youngsu Lim}

Departments of Environmental Engineering, Kyungpook National University, Researcher, ORCID(1) 0000-0002-5443-6438:

Conceptualization, Data curation, Writing - original draft.

\section{Dongwoo Kim}

Environment Management Corporation, Assistant Manager, ORCID (수 0000-0002-8102-8405: Conceptualization, Data curation, Visualization.

\section{Jiseon Jang}

R\&D Institute of Radioactive Wastes, Korea Radioactive Waste Agency, Senior Researcher, ORCID (10) 0000-0003-4619-4405: Data analysis, Methodology, Validation, Writing - review and editing.

\section{Bolam Kim}

Departments of Environmental Engineering, Kyungpook National University, Ph. D. Candidate, ORCID (이 0000-0001-7351-094X: Data analysis, Validation, Visualization.

\section{Dae Sung Lee}

Departments of Environmental Engineering, Kyungpook National University, Professor, ORCID () 0000-0003-3579-0076: Conceptualization, Funding acquisition, Project administration, Resources, Supervision, Writing - review and editing. 